\title{
Phenotype detection of metallo- $\beta$-lactamase among the imipenem resistant Psudomonas and Acinetobacter in the tertiary care hospitals of Dhaka city
}

\author{
Shaheda Anwar ${ }^{*}$, Ruhul Amin \\ From Institut Pasteur International Network Annual Scientific Meeting \\ Hong Kong. 22-23 November 2010
}

Metallo beta lactamases (MBL) are enzymes that have wide spread of activity and they confer a high level of resistance to all $\beta$-lactams including carbapenem, except aztreonam [1]. MBLs require divalent zinc ion for their enzymatic activity which is not diminished by serine $\beta$ lactamase inhibitors like salbactam, tazobactam, clavulinic acid etc but is inhibited by metal chelators like EDTA and thiol based compounds such as 2-mercaptopropionic acid (2-MPA), 10-phenanthroline, calcium dipicholinate etc [2]. They have constant and efficient carbapenemase activity. This MBL production is typically associated with resistance to aminoglycosides and fluoroquinolones further compromising therapeutic options [3].

There are no standard methods for the detection of MBL production in gram negative organism in routine Microbiology practice. The present study was undertaken to evaluate the screening tests like double disk synergy test (DDST) and disk potentiation test (DPT) using ceftazidime (CAZ) and imipenem (IPM) disks with chelating agents like EDTA and 2-MPA. A total of 132 Pseudomonas and 76 Acinetobacter isolates were obtained from Bangabandhu Sheikh Mujib Medical University (BSMMU), Bangladesh Institute of Research and Rehabilitation for Diabetes, and Endocrine and Metabolic disorders (BIRDEM) hospitals of Dhaka city. A total of 53 and 29 IPM resistant Pseudomonas and

Department of Microbiology, Bangabandhu Sheikh Mujib Medical University, Dhaka-1000, Bangladesh
Acinetobacter isolates respectively were selected. EDTAIPM micro dilution minimum inhibitory concentration (EDTA-IPM micro dilution MIC) method detected MBL in 44 (83\%) IPM resistant Pseudomonas and 19(65.5\%) Acinetobacter isolates. DDST with CAZ-0.1M EDTA and CAZ-2-MPA detected MBL in $73.6 \%$ and $67.9 \%$ of IPM resistant Pseudomonas and $55.2 \%$ and $48.3 \%$ of Acinetobacter isolates respectively. The detection rate was 67.9\% and $66.1 \%$ in Pseudomonas and 51.7\% and $44.8 \%$ in Acinetobacter isolates by EDTA-IPM and IPM-2MPA methods respectively. In comparison to DDST, DPT with 0.1M EDTA showed higher sensitivity (89.7\%) and specificity (100\%) for detection of MBL in Pseudomonas and Acinetobacter. Isolates were also tested for AmpC $\beta$ lactamase by DPT using chelating agent - aminophenyl boronic acid (APB) and it detected AmpC $\beta$ lactamase in $6.9 \%$ and $21.1 \%$ MBL positive Pseudomonas and Acinetobacter respectively.

MBL producing Pseudomonas and Acinetobacter are emerging in our country. Rapid detection of these MBLs is necessary to institute appropriate treatment and effective infection control measures. Simple screening test like DPT using CAZ/IPM with 0.1M EDTA can be introduced into the routine clinical laboratories for their early detection.

Published: 10 January 2011 
3. Walsh TR: The emergence and implications of metallo-beta-lactamases in Gram negative bacteria. Clin Microbiol Infect 2005, 11:2-9.

doi:10.1016/S1369-5274(00)00128-4

Cite this article as: Anwar and Amin: Phenotype detection of metallo- $\beta$ -

lactamase among the imipenem resistant Psudomonas and

Acinetobacter in the tertiary care hospitals of Dhaka city. BMC

Proceedings 2011 5(Suppl 1):P92.

Submit your next manuscript to BioMed Central and take full advantage of:

- Convenient online submission

- Thorough peer review

- No space constraints or color figure charges

- Immediate publication on acceptance

- Inclusion in PubMed, CAS, Scopus and Google Scholar

- Research which is freely available for redistribution

Submit your manuscript at www.biomedcentral.com/submit

BioMed Central 